\title{
Reconsolidation and Extinction of Conditioned Fear: Inhibition and Potentiation
}

\author{
Jonathan L. C. Lee, Amy L. Milton, and Barry J. Everitt \\ Department of Experimental Psychology, University of Cambridge, Cambridge CB2 3EB, United Kingdom
}

\begin{abstract}
NMDA receptors are important for the acquisition, reconsolidation, and extinction of memories. NMDA receptor antagonists impair these memory processes, whereas the partial agonist D-cycloserine (DCS) potentiates both learning and extinction. Here, we used DCS and the noncompetitive NMDA receptor antagonist (+)-5-methyl-10,11-dihydro-SH-dibenzo[a,d]cyclohepten-5,10-imine maleate (MK801) to investigate the effects of enhancing and blocking NMDA receptor-mediated glutamatergic transmission on the reconsolidation and extinction of a conditioned fear memory. Either long extinction training or short memory reactivation sessions were used to preferentially engage extinction and reconsolidation processes, respectively. MK-801 blocked extinction to maintain high levels of conditioned freezing, and DCS potentiated extinction to reduce freezing, when they were administered before a long extinction training session. However, the opposite behavioral outcome was observed when the brief memory reactivation session was used: MK-801 administration impaired, whereas DCS increased, freezing, likely reflecting impairment and enhancement of reconsolidation, respectively. Finally, by using localized intracerebral infusions, we showed that the basolateral amygdala is a primary locus of action of systemically administered DCS. Thus, intrabasolateral amygdala DCS potentiated both the extinction and the reconsolidation of fear conditioning, depending on the length of the extinction/memory reactivation session. Therefore, memory reconsolidation can be both disrupted and enhanced, and extinction can be both potentiated and impaired, either to reduce or increase conditioned fear. These results have important implications for the use of reconsolidation blockade and potentiation of extinction as treatment strategies for maladaptive memory disorders.
\end{abstract}

Key words: memory; reconsolidation; extinction; NMDA receptor; basolateral amygdala; rat

\section{Introduction}

Fear conditioning involves the pairing of a previously neutral environmental stimulus, or conditioned stimulus (CS), with an aversive outcome, or unconditioned stimulus (US), as a result of which the CS becomes associated with the US. Subsequent presentations of that CS elicit characteristic fear responses, including conditioned freezing (Blanchard and Blanchard, 1969; Bolles, 1970; Fanselow, 1994). The basolateral amygdala (BLA) is a primary locus of the memory for aversive CS-US associations (Fendt and Fanselow, 1999; LeDoux, 2000; Maren, 2001), and NMDA receptors in the BLA are required for the acquisition of fear conditioning, as demonstrated by studies showing that intraamygdala infusions of NMDA receptor antagonists block the learning of conditioned fear (Campeau et al., 1992; Rodrigues et al., 2001; Goosens and Maren, 2004).

The expression of fear memories can be diminished using two approaches. First, extinction training involves repeated nonreinforced re-exposure to the CS and results in a new memory being formed (CS-no US), and so the fear response to the CS is subse-

Received April 25, 2006; revised July 31, 2006; accepted Aug. 28, 2006.

This work was supported by a grant from the United Kingdom Medical Research Council and was conducted within the Medical Research Council/Wellcome Trust Behavioural and Clinical Neuroscience Institute.

Correspondence should be addressed to Jonathan L. C. Lee, Department of Experimental Psychology, University of Cambridge, Downing Street, Cambridge CB2 3EB, UK. E-mail: jlc12@cam.ac.uk. DOI:10.1523/JNEUROSCI.2466-06.2006

Copyright $\odot 2006$ Society for Neuroscience $\quad$ 0270-6474/06/2610051-06\$15.00/0 quently attenuated (Bouton and Bolles, 1979; Rescorla, 2001). Secondly, the reconsolidation of a previously acquired fear memory, which is required to restabilize the memory after its reactivation through retrieval or CS re-exposure (Nader, 2003; Dudai, 2004; Alberini, 2005), can be disrupted to impair later fear memory expression (Nader et al., 2000; Eisenberg et al., 2003; Lee et al., 2004). Interestingly, the NMDA receptor has been implicated in both extinction and reconsolidation processes. Extinction of conditioned fear is blocked by both systemic and intra-amygdala administration of NMDA receptor antagonists (Falls et al., 1992; Baker and Azorlosa, 1996; Lee and Kim, 1998), whereas it is enhanced by the NMDA receptor partial agonist DCS when administered both systemically and directly into the amygdala (Walker et al., 2002; Ledgerwood et al., 2003). Similarly, the reconsolidation of contextual fear, and spatial and odor-reward memories is impaired by NMDA receptor antagonists (Przybyslawski and Sara, 1997; Suzuki et al., 2004; Torras-Garcia et al., 2005). Therefore, NMDA receptor blockade can both impair extinction to maintain conditioned fear and disrupt reconsolidation to reduce conditioned fear.

A critical parameter that determines whether amnestic treatment will block reconsolidation or extinction is the length of the memory reactivation and extinction training sessions (Eisenberg et al., 2003; Pedreira and Maldonado, 2003; Suzuki et al., 2004). When the session is brief, reconsolidation processes are dominant, whereas longer sessions induce extinction mechanisms 
(Eisenberg et al., 2003). Thus, the opposing effects of NMDA receptor blockade on conditioned fear likely depend on the number of re-exposures to the CS that are presented during the memory reactivation and extinction sessions. Here, we used the noncompetitive NMDA receptor antagonist (+)-5-methyl10,11-dihydro-SH-dibenzo[a,d]cyclohepten-5,10-imine maleate (MK-801), administered systemically, to determine whether the effects of NMDA receptor blockade on conditioned fear do indeed depend on the length of the CS re-exposure session. Furthermore, using systemic and intra-BLA administration of DCS, we tested the prediction that DCS should potentiate extinction when administered before many CS re-exposures as observed previously (Walker et al., 2002; Ledgerwood et al., 2003), but that it should potentiate the reconsolidation of fear memories, and thereby enhance conditioned fear measured subsequently, when administered before a brief memory reactivation session.

\section{Materials and Methods \\ Subjects}

The subjects were 97 adult male Lister hooded rats weighing 250-300 g. They were housed in pairs, in holding rooms maintained at $21^{\circ} \mathrm{C}$ on a reversed-light cycle (12 h light/dark; lights on at 7:00 P.M.). Food and water were freely available throughout the experiment. All procedures were conducted in accordance with the United Kingdom 1986 Animals (Scientific Procedures) Act (project license PPL 80/1767).

\section{Drug administration}

D-Cycloserine and MK-801 (Sigma, Poole, UK) were both dissolved in saline for intraperitoneal injection $(1 \mathrm{ml} / \mathrm{kg})$. The dose of DCS selected $(15 \mathrm{mg} / \mathrm{kg}$ ) has been established previously to facilitate the extinction of conditioned fear memories (Walker et al., 2002; Ledgerwood et al., 2003), and the dose of MK-801 (0.1 mg/kg) both impaired the extinction of fear conditioning (Baker and Azorlosa, 1996) and was higher than that required previously to disrupt the reconsolidation of a spatial memory (0.05 mg/kg) (Przybyslawski and Sara, 1997).

\section{Surgery and infusions}

Thirty-three rats were implanted with bilateral chronic indwelling guide cannulas targeting the BLA. The coordinates for cannula implantation were as follows (relative to bregma): anteroposterior, -2.6 ; mediolateral, \pm 4.5 ; dorsoventral, -5.6 (from dura). Details of the stereotaxic surgical procedures have been described previously (Lee et al., 2004). A minimum of $7 \mathrm{~d}$ was allowed before behavioral training and testing began.

Infusions were performed using a syringe pump, connected to injectors (28 gauge, projecting $2 \mathrm{~mm}$ beyond the guide cannulas) by polyethylene tubing. DCS $(10 \mu \mathrm{g} / 0.5 \mu \mathrm{l} / \mathrm{side} ; 0.25 \mu \mathrm{l} / \mathrm{min})$ was infused $20 \mathrm{~min}$ before the session, and the sterile PBS vehicle was used for control infusions.

\section{Histology}

After completion of behavioral testing, the rats were perfused and their brains cut to produce $60 \mu \mathrm{m}$ coronal sections, which were stained with cresyl violet. Assessment was conducted under light microscopy, and subjects were only included in the statistical analysis if the injectors were located bilaterally within the BLA, and there was no bilateral damage to the amygdala or any other area of the brain.

\section{Behavioral procedures}

Fear conditioning. Fear conditioning took place in four operant chambers as described previously (Lee et al., 2005). On the day before fear conditioning, all rats were habituated to the chambers for $2 \mathrm{~h}$. For fear conditioning, rats were placed again in the operant chambers, and after $30 \mathrm{~min}$ were exposed to two CS-US pairings [ $5 \pm 1 \mathrm{~min}$ interstimulus interval (ISI) ]. The CS was an auditory clicker $(10 \mathrm{~Hz}, 80 \mathrm{~dB}, 60 \mathrm{~s})$ and the US a mild electric footshock $(0.5 \mathrm{~mA}, 0.5 \mathrm{~s})$. Additional groups of rats were fear conditioned using a single CS-US pairing to avoid any ceiling effects.

Memory reactivation and extinction training. On the next day, the rats were administered with DCS or MK-801 30 min before fear memory reactivation or extinction as established previously (Baker and Azorlosa,
1996; Walker et al., 2002). Memory reactivation for the reconsolidation condition consisted of a brief 2 min session in which the rats were exposed to a single presentation of the $60 \mathrm{~s}$ CS after $60 \mathrm{~s}$. In contrast, extinction training involved 10 presentations of the $60 \mathrm{~s}$ CS in a $20 \mathrm{~min}$ session (60 s ISI). Behavior was video-recorded during the first CS presentation of each session and subsequently analyzed for freezing, defined as the lack of movement except for breathing, at $5 \mathrm{~s}$ intervals to give the percentage time freezing during the CS. Additional groups of rats (conditioned with a single CS-US pairing) received injections of saline, MK801 , or DCS, but were not exposed to the CS or the experimental context.

Fear memory testing. Conditioned freezing was tested in 2 min sessions with a single presentation of the $60 \mathrm{~s} C S$ after $60 \mathrm{~s}$. Testing took place $24 \mathrm{~h}$ after extinction training, and $3 \mathrm{~h}$ [post-reactivation short-term memory (PR-STM)], 24 h [post-reactivation long-term memory (PR-LTM)], and $7 \mathrm{~d}$ (PR-LTM2) after memory reactivation for the reconsolidation condition. Behavior was video-recorded during all tests for the subsequent analysis of freezing.

Intra-amygdala infusion of D-cycloserine. For the intra-amygdala study, cannulated rats were conditioned with one CS-US pairing for the memory reactivation condition and five pairings for the extinction condition, in order that the levels of conditioning were similar to those in the systemic drug administration study, because chronic cannulation of the BLA tends to attenuate the expression of conditioned freezing (Fendt, 2001). These rats were infused with DCS or PBS 20 min before exposure to the brief memory reactivation or extinction session, and were tested for conditioned freezing as in the systemic drug administration study.

\section{Statistical analysis}

Data are presented as mean \pm SEM percentage time freezing. Two- or three-way repeated-measures ANOVAs were performed on the data with factors treatment (MK-801 and/or DCS), condition, and test as appropriate. Planned comparisons included MK-801 versus saline and DCS versus saline for both PR-STM versus PR-LTM and PR-STM versus PRLTM2. Tukey's test was selected for post hoc analyses, and a significance level of $p<0.05$ was selected for all analyses.

\section{Results}

\section{Reconsolidation}

The effects of pre-reactivation MK-801 and DCS administration on subsequent conditioned freezing are shown in Figure 1a. MK801 injection resulted in an acute impairment in the expression of conditioned freezing during memory reactivation. ANOVA revealed a significant effect of treatment at the LTM memory reactivation session $\left(F_{(2,21)}=9.11 ; p<0.01\right)$, and post hoc analysis $(p<0.05)$ revealed that the MK-801-, but not the DCS-treated rats were significantly impaired relative to saline injected controls. However, the acute effect of MK-801 was short-lived, as conditioned freezing $3 \mathrm{~h}$ later (PR-STM) did not differ between groups $(\mathrm{F}<1)$.

Subsequently, MK-801 treated rats were impaired, whereas DCS treated rats showed elevated levels of freezing, compared with saline controls. ANOVA revealed a significant overall treatment by test (PR-STM vs PR-LTM vs PR-LTM2) interaction $\left(F_{(4,42)}=11.54 ; p<0.01\right)$. When PR-STM was compared with PR-LTM, there were both significant MK-801 by test $\left(F_{(1,14)}=\right.$ $6.43 ; p<0.03)$ and DCS by test $\left(F_{(1,14)}=15.89 ; p<0.01\right)$ interactions. Furthermore, when PR-STM was compared with PRLTM2, there were again significant MK-801 by test $\left(F_{(1,14)}=\right.$ $5.65 ; p<0.04)$ and DCS by test $\left(F_{(1,14)}=7.33 ; p<0.02\right)$ interactions. Therefore, whereas MK-801 impaired reconsolidation after brief memory reactivation, DCS had the opposite effect, attenuating the progressive diminution of conditioned freezing that is usually observed in control rats during repeated testing.

Additional groups of rats were conditioned using a single CS-US pairing, which resulted in lower levels of conditioned freezing in control rats. Under these conditions, DCS adminis- 
a

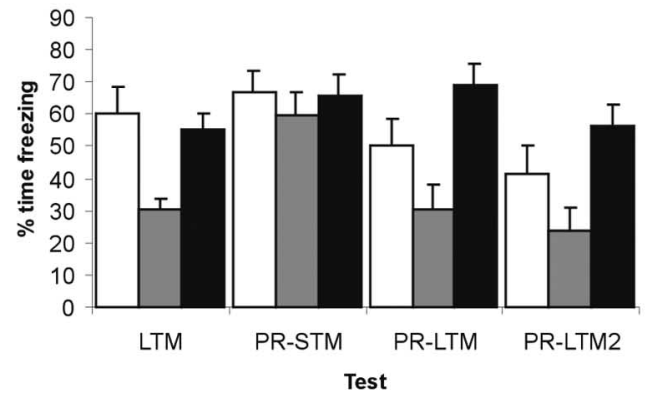

c

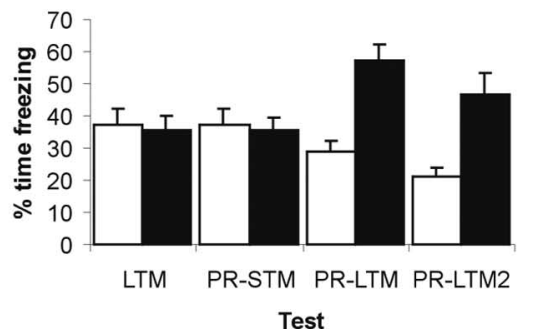

b

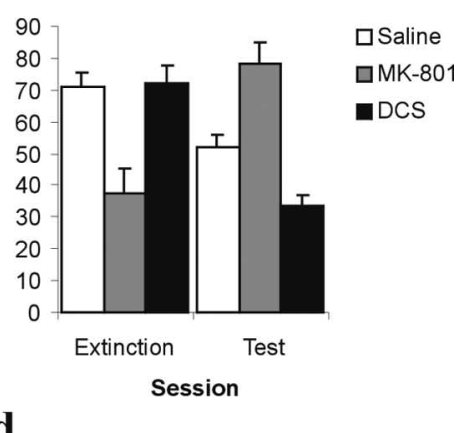

d

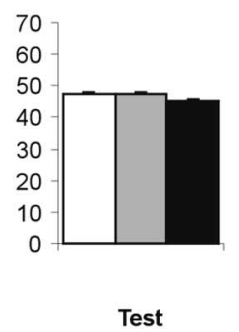

Figure 1. Effects of systemically applied MK- 801 and DCS on conditioned freezing. $\boldsymbol{a}$, When administered before brief memory reactivation (LTM; 1 CS re-exposure), MK-801 had no effect on freezing $3 \mathrm{~h}$ later (PR-STM) but reduced subsequent freezing relative to saline controls both $24 \mathrm{~h}$ (PR-LTM) and $7 \mathrm{~d}$ (PR-LTM2) later. In contrast, DCS attenuated the normal decrement in freezing observed in saline controls in tests PR-LTM and PR-LTM2, although having no effect either acutely or on PR-STM. $\boldsymbol{b}$, When administered before longer extinction training (extinction; 10 CS re-exposures), MK-801 preserved subsequent freezing, whereas DCS enhanced the partial reduction of freezing observed in saline controls. MK-801 also acutely impaired the expression of conditioned freezing in both conditions ( $n=8$ per group). $c$, When fear conditioning was weaker, DCS administration before brief memory reactivation elevated freezing $24 \mathrm{~h}$ and $7 \mathrm{~d}$ later ( $n=8$ per group). $\boldsymbol{d}$, When MK- 801 and DCS were administered without memory reactivation or extinction training, there was no effect on freezing $24 \mathrm{~h}$ later ( $n=8$ per group). Error bars indicate SE.

\section{a}
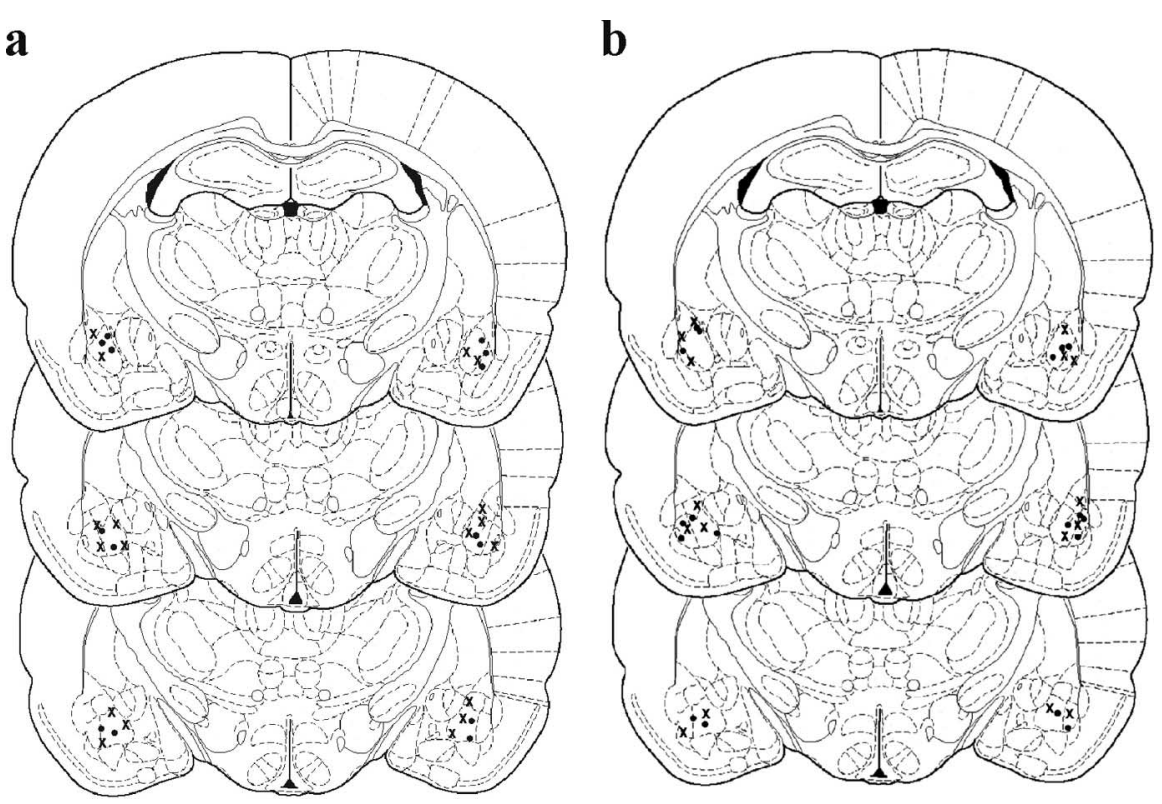

Figure 2. Location of injectors within the BLA. Schematic representation of the brain at three rostrocaudal levels $(-2.30$, -2.56 , and $-2.80 \mathrm{~mm}$ from bregma) (Paxinos and Watson, 1998). All rats included in the statistical analyses had injectors placed bilaterally in the BLA. PBS-infused rats are represented by filled circles, and DCS-infused rats are represented by crosses, for the brief memory reactivation $(\boldsymbol{a})$ and longer extinction $(\boldsymbol{b})$ conditions.

tered at the time of CS re-exposure elevated subsequent conditioned freezing (Fig. 1c). ANOVA revealed a significant overall DCS by test interaction $\left(F_{(3,42)}=18.22 ; p<0.01\right)$, as well as significant DCS by test interactions when PR-STM was compared with PR-LTM $\left(F_{(1,14)}=53.04 ; p<0.01\right)$ and with PR-LTM2 $\left(F_{(1,14)}=16.84 ; p<\right.$ $0.01)$. Importantly, whereas conditioned freezing in control rats diminished with repeated testing $\left(F_{(3,21)}=15.40 ; p<0.01\right)$, freezing levels increased after DCS treatment $\left(F_{(3,21)}=9.65 ; p<0.01\right)$. Therefore, DCS potentiated fear memory reconsolidation to elevate conditioned freezing measured subsequently during CS presentations.

\section{Extinction}

The effects of MK-801 and DCS administration before an extinction training session on subsequent conditioned freezing are shown in Figure 1b. MK-801 injection again resulted in an acute impairment in the expression of conditioned freezing during memory extinction. ANOVA revealed a significant effect of treatment at the extinction training session $\left(F_{(2,21)}=\right.$ $11.03 ; p<0.01)$, and post hoc analysis $(p<0.05)$ revealed that the MK-801-, but not the DCS-treated rats were significantly impaired relative to saline-injected controls.

Subsequently at test, MK-801-treated rats showed elevated, and DCS-treated rats reduced, levels of freezing compared with saline controls. ANOVA revealed a significant effect of treatment $\left(F_{(2,21)}=23.83\right.$; $p<0.01)$, and post hoc analysis $(p<0.05)$ revealed that both the MK-801 and DCS groups differed from the saline group and from each other. Therefore, MK-801 impaired, and DCS potentiated, the extinction of conditioned fear after extended CS re-exposure.

Rats injected with DCS or MK-801, but not exposed to the memory reactivation or extinction sessions froze at the same level as saline treated controls (Fig. 1d). ANOVA revealed no effect of treatment on freezing levels $24 \mathrm{~h}$ after injection $(F<1)$. Thus, the fear memory is fully consolidated $24 \mathrm{~h}$ after acquisition, and the previously observed effects of MK-801 and DCS injection to increase or decrease subsequent freezing are dependent on the stimulus re-exposure during the memory reactivation and extinction sessions.

\section{Intra-amygdala D-cycloserine}

All rats included in the behavioral analyses had cannulas placed bilaterally in the BLA (Fig. 2). The effect of intra-BLA infusion of DCS before brief re-exposure is shown in Figure $3 a$. ANOVA revealed a significant overall DCS by test interaction $\left(F_{(3,42)}=13.20 ; p<0.01\right)$. Whereas there was no difference between the groups during the LTM reactivation and PR-STM sessions $(F<1)$, analysis of PRSTM and PR-LTM tests revealed a significant DCS by test inter- 
action $\left(F_{(1,14)}=41.48 ; p<0.01\right)$, with no main effect of DCS $\left(F_{(1,14)}=1.31 ; p>\right.$ $0.27)$, and comparison of PR-STM and PR-LTM2 also revealed a significant DCS by test interaction $\left(F_{(1,14)}=28.74 ; p<\right.$ $0.01)$ with no main effect of DCS $\left(F_{(1,14)}=\right.$ $3.49 ; p>0.08)$. Moreover, analysis of the DCS-infused group alone demonstrated that freezing levels were significantly increased at tests PR-LTM and PR-LTM2 compared with PR-STM ( $p$ values $<$ 0.01). Therefore, pre-reactivation intraBLA DCS potentiated memory reconsolidation to elevate subsequent freezing levels.

In contrast, when DCS was infused into the BLA before more prolonged CS reexposure, subsequent freezing was reduced compared with PBS infused controls (Fig. 3b). ANOVA revealed a significant DCS by test interaction $\left(F_{(1,15)}=5.65 ; p<\right.$ $0.04)$, with no main effect of DCS $\left(F_{(1,15)}=1.46 ; p>0.24\right)$, and there was no acute effect of DCS on the extinction session $(F<1)$. Therefore, whereas controls displayed reduced freezing levels at test compared with during extinction, freezing in DCS-infused rats decreased to a significantly greater extent, demonstrating a potentiation of extinction. An overall analysis of both reactivation conditions (using tests LTM and PR-LTM for the short reactivation condition) revealed a significant DCS by condition by test interaction $\left(F_{(1,29)}=11.46 ; p<0.01\right)$, confirming that the effect of DCS on freezing was dependent on the length of, and therefore the degree of extinction occurring within, the reactivation session.

\section{Discussion}

The present results demonstrate that blockade of NMDA receptors by the noncompetitive antagonist MK-801 impairs both the reconsolidation and extinction of conditioned fear memories, depending on the number of CS re-exposures presented during the memory reactivation/extinction session. In contrast, enhancement of NMDA receptor-mediated glutamatergic transmission by DCS potentiates the extinction of conditioned freezing when the CS is re-exposed many times, and also enhances reconsolidation when administered before a single CS presentation. Furthermore, we show that a primary locus of action of DCS is the BLA, because intra-BLA infusions of DCS also potentiate extinction and reconsolidation under different experimental conditions.

Studies of the competition between extinction and reconsolidation have demonstrated that the extent to which memory reactivation also induces extinction has a significant impact on the behavioral effect of amnestic treatment (Eisenberg et al., 2003; Pedreira and Maldonado, 2003; Suzuki et al., 2004). When stimulus re-exposure during memory reactivation is brief compared with the strength of conditioning, little extinction is induced and so protein synthesis inhibition disrupts the dominant reconsolidation process, resulting in reduced memory expression (Eisenberg et al., 2003; Pedreira and Maldonado, 2003; Suzuki et al., 2004). In contrast, when the reactivation session induces significant extinction, protein synthesis inhibition impairs the now dominant extinction process, resulting in preserved memory expression. Thus, the effect of protein synthesis inhibition depends critically on the dominant memory process that is engaged at the time of treatment (Eisenberg et al., 2003). The present experi- b

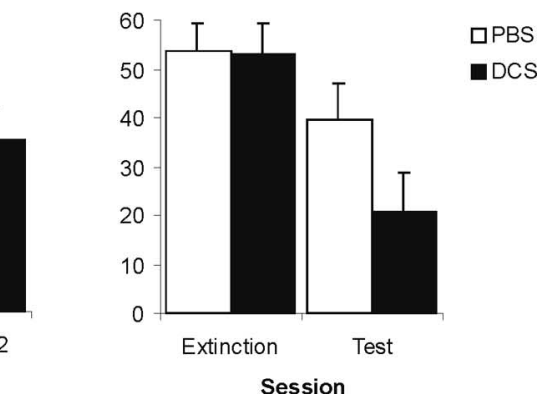

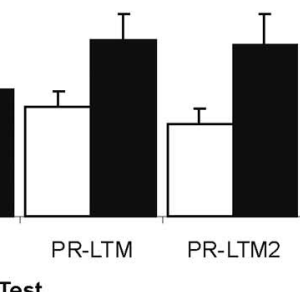

Figure 3. Effects of DCS infusion into the BLA on conditioned freezing. $\boldsymbol{a}$, When infused before brief memory reactivation (LTM; administered before longer extinction training (extinction; 10 CS re-exposures), DCS enhanced the partial reduction of freezing 7-9 per group). Error bars indicate $S E$.

ments revealed an identical pattern of results using systemically administered MK-801 to block both fear memory reconsolidation and extinction. Furthermore, systemic or intra-amygdala DCS, which enhances NMDA receptor-mediated glutamatergic transmission (Rouaud and Billard, 2003), resulted in the opposite pattern of results, reducing memory expression when infused before a long extinction session, and preserving/elevating memory expression when infused before a short reactivation session. Therefore, DCS potentiated fear memory extinction, as has been demonstrated previously (Walker et al., 2002; Ledgerwood et al., 2003). Moreover, given that it is highly unlikely that the same infusion of DCS could both enhance and prevent extinction, and that DCS potentiates a range of learning processes (Monahan et al., 1989; Quartermain et al., 1994; Land and Riccio, 1999; Walker et al., 2002; Ledgerwood et al., 2003), the elevated freezing and lack of extinction after DCS infusion before short memory reactivation likely reflects a potentiation of conditioned fear memory reconsolidation. Reconsolidation and extinction have opposing effects on behavioral output, and so an enhancement of reconsolidation would act against the behavioral impact of extinction. When baseline levels of freezing averaged $65 \%$, DCS protected against extinction, maintaining the already high levels of freezing. However, when a weaker fear conditioning protocol was used, resulting in baseline freezing levels of $<40 \%$, DCS potentiated subsequent freezing to $60 \%$. Thus, the failure to observe an increase in freezing levels in Figure $1 a$ likely reflects a "ceiling effect" as a result of the high baseline levels of freezing.

Reconsolidation enhancement has been observed previously with the use of systemic treatments such as glucose (Rodriguez et al., 1999) and strychnine (Gordon, 1977), as well as more recently after protein kinase A (PKA) activation in the amygdala (Tronson et al., 2006). NMDA receptor antagonists impair both extinction (Falls et al., 1992; Lee and Kim, 1998) and reconsolidation (Suzuki et al., 2004; Torras-Garcia et al., 2005), and so it is not unexpected that DCS potentiates the extinction and reconsolidation of reactivated memories under different circumstances. That the direction of the effects of DCS, as well as MK-801, changes depending on the degree of CS re-exposure is particularly important. Usually, nonreactivated and nonextinguished controls would be necessary to rule out the possibility that agents affect memory directly in a manner that is not dependent on the memory reactivation or extinction session. However, given that MK801 does not directly affect the expression of conditioned fear $3 \mathrm{~h}$ later (PR-STM) (Fig. 1), and that MK-801 can elevate conditioned freezing when administered before extinction training, its 
effects to reduce freezing must be critically dependent on the single CS re-exposure during memory reactivation. In the present study, the nonreactivated/nonextinguished controls further confirm that the administration of MK-801 and DCS does not have any nonspecific effects on subsequent freezing, demonstrating that the fear memory is fully consolidated $1 \mathrm{~d}$ after acquisition. Thus, MK-801 disrupted fear memory reconsolidation, and the same logic can be applied to demonstrate that MK-801 impaired extinction. Similarly, because DCS either reduced or enhanced subsequent conditioned freezing when administered before long or short CS re-exposure sessions, and DCS alone has been shown previously not to affect conditioned fear $24 \mathrm{~h}$ later (Walker et al., 2002; Ledgerwood et al., 2003), we can conclude that DCS potentiates both the extinction and reconsolidation of conditioned fear memories.

NMDA receptors have been strongly implicated in mechanisms underlying learning and memory (Riedel et al., 2003). Not only does blockade of NMDA receptor transmission impair the acquisition of several forms of memory (Morris et al., 1986; Campeau et al., 1992; Burns et al., 1994; Maren et al., 1996; Ferry and Di Scala, 2000; Rodrigues et al., 2001; Goosens and Maren, 2004) and disrupt acutely the expression of previously acquired fear memories (Maren et al., 1996; Fendt, 2001; Lee et al., 2001) as observed here, but administration of partial NMDA receptor agonists also enhances learning (Monahan et al., 1989; Thompson et al., 1992; Quartermain et al., 1994; Land and Riccio, 1999). The extinction of conditioned fear memories, which involves new learning (Bouton and Bolles, 1979; Rescorla, 2001), has also been shown previously to be impaired by NMDA receptor antagonists (Falls et al., 1992; Baker and Azorlosa, 1996; Lee and Kim, 1998) and potentiated by the partial NMDA receptor agonist DCS (Walker et al., 2002; Ledgerwood et al., 2003), when these compounds are administered either systemically or directly into the BLA. The present results, using systemic MK-801 to block fear memory extinction and both systemic and intra-BLA DCS to potentiate extinction of conditioned freezing, both reinforce and extend these findings.

There is also previous evidence that NMDA receptors are involved in the reconsolidation of memories after CS re-exposure. Systemic MK-801 and CPP [D(-)-3-(2-carboxypiperazin-4-yl)propyl-1-phosphonic acid] impaired the reconsolidation of a spatial memory (Przybyslawski and Sara, 1997) and a contextual fear memory (Suzuki et al., 2004). Furthermore, intracerebroventricular AP-5 disrupted the reconsolidation of an odor-reward association (Torras-Garcia et al., 2005). Here, we show further that systemic MK-801 also blocked the reconsolidation of a discrete conditioned fear memory. In contrast, systemic administration of DCS before brief CS re-exposure potentiated fear memory reconsolidation. This finding was replicated when DCS was infused directly into the BLA, indicating that the BLA is a primary locus of action of the effects of DCS to enhance reconsolidation. Thus, NMDA receptors in the BLA are important for the reconsolidation of fear memories conditioned to a discrete CS. It can further be hypothesized that the effects of NMDA receptor antagonism/partial agonism may be mediated by PKA, as the present effects on memory reconsolidation are similar to those observed after PKA inhibition and activation (Tronson et al., 2006).

Reactivation-related protein synthesis-dependent amnesia is generally considered to result from a disruption of reconsolidation (Nader, 2003; Alberini, 2005). However, it is also possible that the reduction in performance could be explained simply as a potentiation of extinction (Fischer et al., 2004). Such an explana- tion has been excluded previously in studies of conditioned fear through the use of reinforced reactivation procedures (Duvarci and Nader, 2004; Eisenberg and Dudai, 2004). The opposing effects of DCS and MK-801 in the present study after a short memory reactivation session further emphasize the distinction between these processes. If the MK-801 induced reduction in conditioned freezing is indeed a result of potentiated extinction, DCS treatment, which is known to enhance extinction processes (Walker et al., 2002; Ledgerwood et al., 2003), should have had the same memory-impairing effect, rather than the observed gain of function demonstrated here.

Both reconsolidation blockade and potentiation of extinction have been proposed as potential approaches to the treatment of maladaptive memory disorders such as post-traumatic stress, phobias, and drug addiction (Davis, 2002; Walker et al., 2002; Nader, 2003; Lee et al., 2004, 2005; Richardson et al., 2004). The present results indicate that the successful application of such approaches will depend critically on the parameters of reexposure to the CS during memory reactivation or extinction training. When using reconsolidation blockade, if memory reactivation is too extensive, amnestic agents will impair extinction rather than reconsolidation. Furthermore, when attempting to potentiate extinction, if the extinction training is too limited, reconsolidation processes may be preferentially enhanced by drugs such as DCS. Therefore, if the parameters of CS reexposure are not selected carefully, in accordance with the degree of conditioning, there is a great risk that the maladaptive memory will be preserved or even strengthened by attempts to block its reconsolidation or potentiate its extinction. Agents that dissociably potentiate extinction but not reconsolidation, or impair reconsolidation but not extinction may therefore be particularly useful in the treatment of maladaptive memory disorders.

\section{References}

Alberini CM (2005) Mechanisms of memory stabilization: are consolidation and reconsolidation similar or distinct processes? Trends Neurosci 28:51-56.

Baker JD, Azorlosa JL (1996) The NMDA antagonist MK-801 blocks the extinction of Pavlovian fear conditioning. Behav Neurosci 110:618-620.

Blanchard RJ, Blanchard DC (1969) Crouching as an index of fear. J Comp Physiol Psychol 67:370-375.

Bolles RC (1970) Species-specific defense reactions and avoidance learning. Psychol Rev 17:32-48.

Bouton ME, Bolles RC (1979) Contextual control of the extinction of conditioned fear. Learn Motiv 10:445-466.

Burns LH, Everitt BJ, Robbins TW (1994) Intra-amygdala infusion of the $\mathrm{N}$-Methyl-D-Aspartate receptor antagonist AP5 impairs acquisition but not performance of discriminated approach to an appetitive CS. Behav Neural Biol 61:242-250.

Campeau S, Miserendino MJD, Davis M (1992) Intra-amygdala infusion of the $N$-Methyl-D-Aspartate receptor antagonist Ap 5 blocks acquisition but not expression of fear-potentiated startle to an auditory conditionedstimulus. Behav Neurosci 106:569-574.

Davis M (2002) Role of NMDA receptors and MAP kinase in the amygdala in extinction of fear: clinical implications for exposure therapy. Eur J Neurosci 16:395-398.

Dudai Y (2004) The neurobiology of consolidations, or, how stable is the engram? Annu Rev Psychol 55:51-86.

Duvarci S, Nader K (2004) Characterization of fear memory reconsolidation. J Neurosci 24:9269-9275.

Eisenberg M, Dudai Y (2004) Reconsolidation of fresh, remote, and extinguished fear memory in Medaka: old fears don't die. Eur J Neurosci 20:3397-3403.

Eisenberg M, Kobilo T, Berman DE, Dudai Y (2003) Stability of retrieved memory: inverse correlation with trace dominance. Science 301:1102-1104.

Falls WA, Miserendino MJ, Davis M (1992) Extinction of fear-potentiated 
startle: blockade by infusion of an NMDA antagonist into the amygdala. J Neurosci 12:854-863.

Fanselow MS (1994) Neural organization of the defensive behavior system responsible for fear. Psychon Bull Rev 1:429-438.

Fendt M (2001) Injections of the NMDA receptor antagonist aminophosphonopentanoic acid into the lateral nucleus of the amygdala block the expression of fear-potentiated startle and freezing. J Neurosci 21:4111-4115.

Fendt M, Fanselow MS (1999) The neuroanatomical and neurochemical basis of conditioned fear. Neurosci Biobehav Rev 23:743-760.

Ferry B, Di Scala G (2000) Basolateral amygdala NMDA receptors are selectively involved in the acquisition of taste-potentiated odor aversion in the rat. Behav Neurosci 114:1005-1010.

Fischer A, Sananbenesi F, Schrick C, Spiess J, Radulovic J (2004) Distinct roles of hippocampal de novo protein synthesis and actin rearrangement in extinction of contextual fear. J Neurosci 24:1962-1966.

Goosens KA, Maren S (2004) NMDA receptors are essential for the acquisition, but not expression, of conditional fear and associative spike firing in the lateral amygdala. Eur J Neurosci 20:537-548.

Gordon WC (1977) Susceptibility of a reactivated memory to the effects of strychnine: a time-dependent phenomenon. Physiol Behav 18:95-99.

Land C, Riccio DC (1999) D-Cycloserine: effects on long-term retention of a conditioned response and on memory for contextual attributes. Neurobiol Learn Mem 72:158-168.

Ledgerwood L, Richardson R, Cranney J (2003) Effects of D-cycloserine on extinction of conditioned freezing. Behav Neurosci 117:341-349.

LeDoux JE (2000) Emotion circuits in the brain. Annu Rev Neurosci 23:155-184.

Lee H, Kim JJ (1998) Amygdalar NMDA receptors are critical for new fear learning in previously fear-conditioned rats. J Neurosci 18:8444-8454.

Lee HJ, Choi JS, Brown TH, Kim JJ (2001) Amygdalar NMDA receptors are critical for the expression of multiple conditioned fear responses. J Neurosci 21:4116-4124.

Lee JL, Everitt BJ, Thomas KL (2004) Independent cellular processes for hippocampal memory consolidation and reconsolidation. Science 304:839-843.

Lee JL, Di Ciano P, Thomas KL, Everitt BJ (2005) Disrupting reconsolidation of drug memories reduces cocaine seeking behavior. Neuron $47: 795-801$.

Maren S (2001) Neurobiology of Pavlovian fear conditioning. Annu Rev Neurosci 24:897-931.

Maren S, Aharonov G, Stote DL, Fanselow MS (1996) N-methyl-Daspartate receptors in the basolateral amygdala are required for both acquisition and expression of conditional fear in rats. Behav Neurosci 110:1365-1374.

Monahan JB, Handelmann GE, Hood WF, Cordi AA (1989) D-cycloserine, a positive modulator of the $N$-methyl-D-aspartate receptor, enhances performance of learning tasks in rats. Pharmacol Biochem Behav 34:649-653.

Morris RG, Anderson E, Lynch GS, Baudry M (1986) Selective impairment of learning and blockade of long-term potentiation by an $N$-methyl-Daspartate receptor antagonist, AP5. Nature 319:774-776.

Nader K (2003) Memory traces unbound. Trends Neurosci 26:65-72.

Nader K, Schafe GE, Le Doux JE (2000) Fear memories require protein synthesis in the amygdala for reconsolidation after retrieval. Nature 406:722-726.

Paxinos G, Watson C (1998) The rat brain in stereotaxic coordinates, Ed 4. London: Academic.

Pedreira ME, Maldonado H (2003) Protein synthesis subserves reconsolidation or extinction depending on reminder duration. Neuron 38:863-869.

Przybyslawski J, Sara SJ (1997) Reconsolidation of memory after its reactivation. Behav Brain Res 84:241-246.

Quartermain D, Mower J, Rafferty MF, Herting RL, Lanthorn TH (1994) Acute but not chronic activation of the NMDA-coupled glycine receptor with D-cycloserine facilitates learning and retention. Eur J Pharmacol 257:7-12.

Rescorla RA (2001) Experimental extinction. In: Handbook of contemporary learning theories (Mowrer RR, Klein S, eds), pp 119-154. Mahwah: Erlbaum.

Richardson R, Ledgerwood L, Cranney J (2004) Facilitation of fear extinction by D-cycloserine: theoretical and clinical implications. Learn Mem 11:510-516.

Riedel G, Platt B, Micheau J (2003) Glutamate receptor function in learning and memory. Behav Brain Res 140:1-47.

Rodrigues SM, Schafe GE, LeDoux JE (2001) Intra-amygdala blockade of the NR2B subunit of the NMDA receptor disrupts the acquisition but not the expression of fear conditioning. J Neurosci 21:6889-6896.

Rodriguez WA, Horne CA, Padilla JL (1999) Effects of glucose and fructose on recently reactivated and recently acquired memories. Prog Neuropsychopharmacol Biol Psychiatry 23:1285-1317.

Rouaud E, Billard JM (2003) D-cycloserine facilitates synaptic plasticity but impairs glutamatergic neurotransmission in rat hippocampal slices. $\mathrm{Br} \mathrm{J}$ Pharmacol 140:1051-1056.

Suzuki A, Josselyn SA, Frankland PW, Masushige S, Silva AJ, Kida S (2004) Memory reconsolidation and extinction have distinct temporal and biochemical signatures. J Neurosci 24:4787-4795.

Thompson LT, Moskal JR, Disterhoft JF (1992) Hippocampus-dependent learning facilitated by a monoclonal antibody or D-cycloserine. Nature 359:638-641.

Torras-Garcia M, Lelong J, Tronel S, Sara SJ (2005) Reconsolidation after remembering an odor-reward association requires NMDA receptors. Learn Mem 12:18-22.

Tronson NC, Wiseman SL, Olausson P, Taylor JR (2006) Bidirectional behavioral plasticity of memory reconsolidation depends on amygdalar protein kinase A. Nat Neurosci 9:167-169.

Walker DL, Ressler KJ, Lu KT, Davis M (2002) Facilitation of conditioned fear extinction by systemic administration or intra-amygdala infusions of D-cycloserine as assessed with fear-potentiated startle in rats. J Neurosci 22:2343-2351. 